\title{
Photoredox Organocatalysis: Asymmetric $\alpha$-Perfluoroalkylation of Aldehydes
}

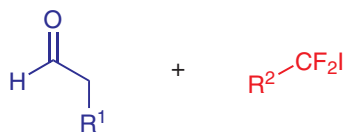
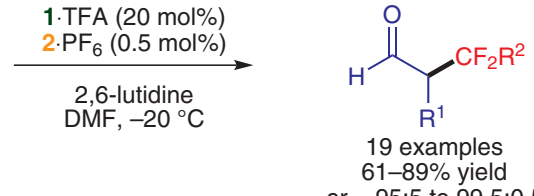

Proposed catalytic cycles:

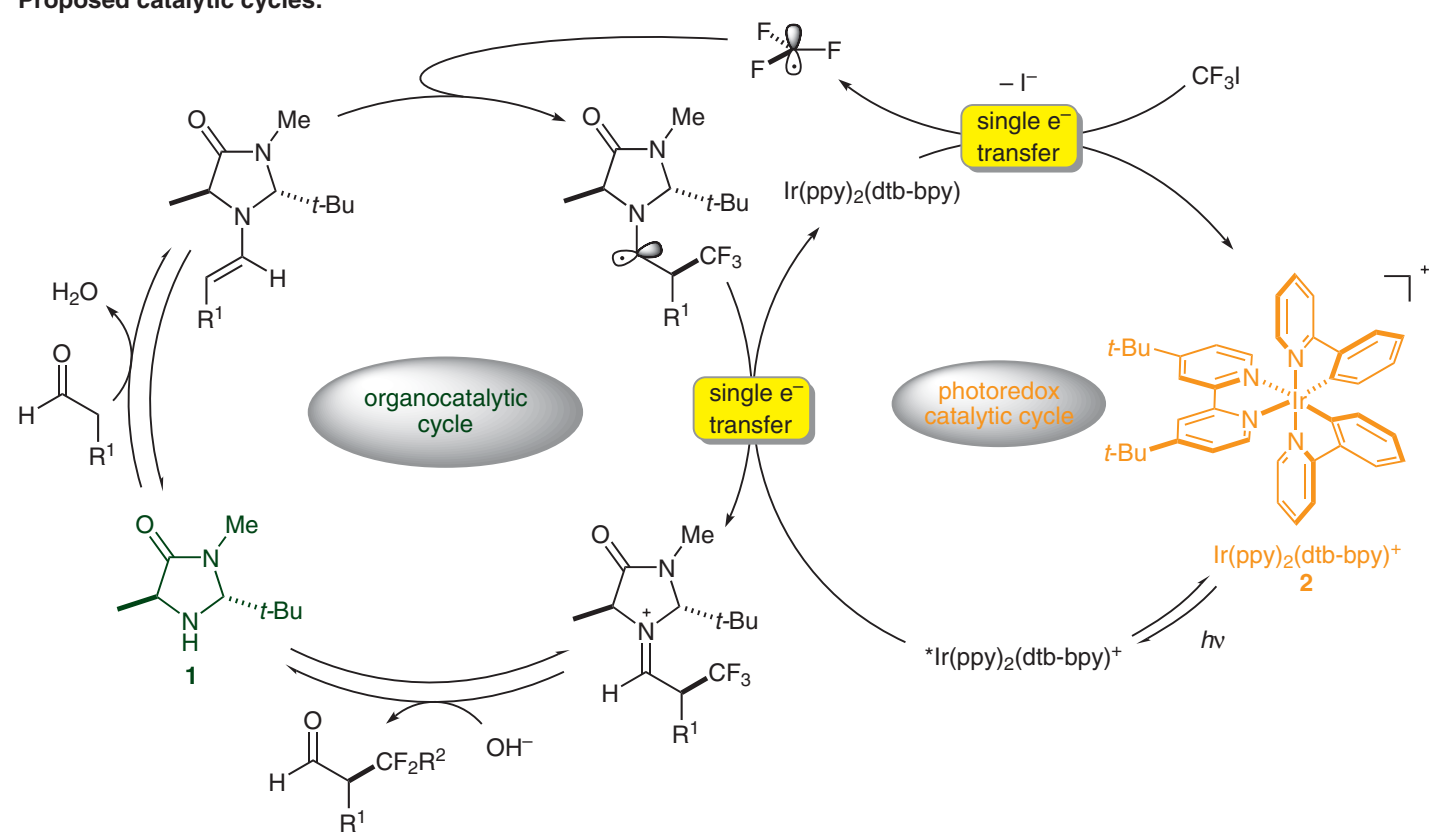

Significance: MacMillan and co-workers report an efficient and highly enantioselective $\alpha$-perfluoroalkylation of aldehydes employing photoredox organocatalysis. The proposed mechanism involves an organocatalytic and a photoredox cataIytic cycle. The organocatalyst $\mathbf{1}$ reacts with the aldehyde to form an enamine intermediate which reacts with the trifluoromethyl radical, formed in the photoredox catalytic cycle. The resulting $\alpha$ amino radical is oxidized by an excited state species of the photocatalyst $\mathbf{2}$, generated by irradiation. The reduced photocatalyst is reoxidized by trifluoromethyliodide to give $\mathbf{2}$ and a new trifluoromethyl radical.
Comment: Since fluorine-containing molecules exhibit interesting biological properties, their stereoselective synthesis has gained much interest during the last years. Herein, the authors present a very sophisticated strategy for the asymmetric $\alpha$-trifluoromethylation of aldehydes based on their previously introduced concept of merging organocatalysis with photoredox catalysis (Science 2008, 322, 77). The products are obtained in high enantioselectivities and can be converted into other useful enantioenriched fluorine-containing compounds as shown nicely by the authors. Further applications of these coupled catalytic cycles can be expected.

SYNFACTS Contributors: Benjamin List, Steffen Müller DoI: 10.1055/s-0029-1217944; Reg-No.: B09709SF 